\title{
“UN ESPACIO PARA EL SER HUMANO Y LA NATURALEZA". REFLEXIONES A PARTIR DE LA PROPUESTA DE MORATORIA URBANÍSTICA A NIVEL CONSTITUCIONAL EN SUIZA ${ }^{1}$
}

\author{
JORDI JARIA I MANZANO \\ Profesor lector de Derecho Constitucional \\ Universitat Rovira i Virgili \\ Investigador \\ Centre d'Estudis de Dret Ambiental de Tarragona (CEDAT) \\ jordi.jaria@urv.cat
}

Recibido: 2 de mayo de 2011 / Aceptado: 26 de mayo de 2011

RESUMEN: El 10 de julio de 2007 se lanzó la iniciativa popular de reforma de la Constitución federal suiza conocida con el nombre de "Iniciativa para el paisaje" (Landschaftsinitiative, Initiative pour le paysage). La iniciativa incluye una propuesta de modificación del artículo 75 de la Constitución, en materia de ordenación del territorio, y una innovadora (y radical) propuesta de adición de una disposición transitoria a la Constitución que implicaría, en caso de aprobarse, una moratoria urbanística de veinte años, esto es, la prohibición de ampliar el suelo edificable durante ese período de tiempo. Después de la verificación del cumplimiento de los requisitos formales para su presentación (en particular, el número de firmas recogidas), se dio

\footnotetext{
${ }^{1}$ Este trabajo fue presentado como comunicación en las jornadas I Encuentros junto al Mar. Acoso al Territorio, organizadas por la Facultad de Derecho de la Universidad de Cantabria los días 13 y 14 de abril de 2011, y se enmarca dentro del proyecto de investigación "Estado autonómico y democracia: los derechos de participación en los Estatutos de Autonomía”, financiado por el Ministerio de Ciencia e Innovación para el trienio 2009-2012 (DER2009-12921/subprograma JURI; investigador principal: Josep M. Castellà Andreu).
} 
trámite a la iniciativa. Actualmente, después que el Consejo Federal hiciera una contrapropuesta, en el sentido de modificar la legislación federal de ordenación del territorio, rechazando, en particular, la moratoria urbanística, el proceso se halla en la fase de tramitación por parte de la Asamblea Federal, sin que aún se haya sometido a referéndum. La iniciativa y el debate suscitado subsiguientemente pueden ser de algún interés para la situación en España, dada la dependencia de esta del sector de la construcción, la grave crisis que este atraviesa y el considerable impacto en el territorio que su actividad ha tenido en los momentos de mayor auge.

RESUM: El 10 de juliol de 2007 es va llançar la iniciativa popular de reforma de la Constitució federal suïssa coneguda amb el nom d'“Iniciativa per al paisatge" (Landschaftsinitiative, Iniatiative pour le paysage). La iniciativa inclou una proposta de modificació de l'article 75 de la Constitució, relatiu a l'ordenació del territori, i una innovadora (i radical) proposta d'addició d'una disposició transitòria a la Constitució que implicaria, en cas d'aprovar-se, una moratòria urbanística de vint anys, això és, la prohibició d'ampliar el sòl edificable durant aquest període de temps. Després de la verificació del compliment dels requisits formals per a la seva presentació (en particular, el nombre de firmes recollides) es va donar tràmit a la iniciativa. Actualment, després de què el Consell Federal fes una contraproposta, en el sentit de modificar la legislació federal d'ordenació del territori, tot rebutjant, en particular la moratòria urbanística, el procés es troba en fase de tramitació per part de l'Assemblea Federal, sense que encara s'hagi sotmès a referèndum. La iniciativa $i$ el debat suscitat subsegüentment poden ser d'algun interès per a la situació a Espanya, atesa la dependència d'aquesta del sector de la construcció, la greu crisi que aquest travessa i el considerable impacte en el territori que la seva activitat ha tingut en els moments de més grau auge.

ABSTRACT: On July 10th 2007 the initiative to amend the Swiss Federal Constitution named "Initiative for the Landscape" (Landschaftsinitiative, Iniatiative pour le paysage) was launched. The initiative includes a proposal of amendment of article 75 of the Constitution, regarding spatial planning and urban development, and an innovative (and radical) proposal to add a transitory provision to the Constitution that would imply, if 
passed, an urban development moratorium of twenty years, i.e., the prohibition of extend the land where urban development is allowed during this period of time. After the verification of the fulfilment of the formal requirements for its presentation (particularly, the number of signatures required) the procedure started. Nowadays, after the Federal Council made a counterproposal, aimed to amend the regulation on urban development and spatial planning, refusing the moratorium, the procedure is now in the phase of examination by the Federal Assembly, waiting for the referendum which has to put an end to it. The initiative and the following debate can be of some interest in Spain, given the fact of its dependency on building sector, the deep crisis affecting it and the considerable impact that it have had in the territory in the moments of more activity.

PALABRAS CLAVE: moratoria urbanística — ordenación del territorio - protección del paisaje - democracia

PARAULES CLAU: moratòria urbanística - ordenació del territori — protecció del paisatge - democràcia

KEY WORDS: urban development moratorium - deforestation - landscape protection - democracy

Sumario: I. Cuestiones previas: democracia directa a nivel federal en Suiza (las iniciativas populares de reforma constitucional). II. La "Iniciativa para el paisaje". 1. Origen y contenidos. 2. La contrapropuesta del Consejo Federal. 3. El debate actual y las consecuencias posibles del referéndum. III. De lo particular a lo general. Urbanismo y medio ambiente. 1. La ordenación del territorio y el urbanismo como instrumentos para la gestión del espacio. 2. La vulnerabilidad del territorio y las necesidades sociales. IV. Desarrollo sostenible, principio de precaución y principio de cooperación en la ordenación del territorio: reflexiones a propósito del caso suizo. V. Bibliografía. 


\section{CUESTIONES PREVIAS: DEMOCRACIA DIRECTA A NIVEL FEDERAL EN SUIZA (LAS INICIATIVAS POPULARES DE REFORMA CONSTITUCIONAL) $)^{2}$}

La democracia es un elemento sustancial de la idea suiza de Estado, quizá el más importante junto con el federalismo. La democracia suiza se caracteriza por dos rasgos esenciales que la distinguen de lo que es habitual en los Estados europeos de su entorno, a saber, el hecho de que se trata de una democracia directa y de concordancia. Contrariamente a lo que sucede en casos como el británico, el alemán o el español, no existe en Suiza una desconfianza en relación con la atribución directamente al pueblo de facultades de decisión política, esto es, sin la mediación de las instituciones representativas, sino todo lo contrario. En efecto, Suiza es seguramente el ejemplo más claro de democracia directa que existe, al menos en Europa. Esto es así no por la existencia de la institución del referéndum o de la iniciativa popular —en el caso suizo, además, limitada a la iniciativa de reforma de la Constitución en el plano federal一, sino porque la convocatoria de referéndum depende del propio cuerpo electoral, sea en el caso de referéndum facultativo en relación con las leyes federales, sea en el caso de iniciativa popular de reforma de la Constitución ${ }^{3}$.

La fortaleza de los procesos de democracia directa, tanto a nivel cantonal como a nivel federal — me voy a concentrar en este trabajo en este último plano-, está vinculada a una tradición democrática que tiene que ver con la propia cultura constitucional y con la propia idea suiza de democracia, esto es, lo que se ha dado en llamar la democracia de concordancia ${ }^{4}$. Efectivamente, contrariamente al énfasis en la regla de la mayoría y a la importancia de la alternancia política en los distintos sistemas parlamentarios, la democracia suiza se basa en la búsqueda de consensos y en la creación de un amplio espacio político central, lo que se refleja, por ejemplo, en la pervivencia de la misma

\footnotetext{
${ }^{2}$ En relación con el funcionamiento de la democracia directa en Suiza, vid. mi trabajo "Las consultas populares en Suiza (Un estudio sobre la democracia directa)", Jus. Revista del Instituto de Investigaciones Jurídicas de la UJED, núm. 17, enero-junio 2009, pp. 127-144. Para una contextualización de la democracia directa en el marco del sistema y la cultura constitucionales suizas, vid., asimismo, mi trabajo "El federalismo suizo. Una respuesta a una sociedad plural”, Revista Vasca de Administración Pública / Herri-Arduralaritzako Euskal Aldizkaria, núm. 61 (I), septiembre-diciembre 2001, pp. 89-136.

${ }^{3}$ Vid., en este sentido, AUER, A., MALINVERNI, G., HOTTELIER, M., Droit constitutionnel suisse. 1. L'Etat, Staempfli, Berna, 2000, p. 191.

4 Así, por ejemplo, vid. RHINOW, R., "Die Regierungsreform im Bund”, Zen-Ruffinen, P., Auer, A. (eds.), De la Constitution. Études en l'honneur de Jean-François Aubert, Helbing \& Lichtenhahn, Basilea-Frankfurt am Main, 1996, p. 90.
} 
coalición de gobierno desde los años cincuenta ${ }^{5}$. Por lo tanto, el referéndum no se concibe como un proceso destinado a imponer decisiones a la minoría, sino como un instrumento para la generación de consenso social en torno a las decisiones políticas.

Uno de los elementos centrales a nivel federal del sistema político-constitucional suizo es la iniciativa popular de reforma constitucional. Se trata de una iniciativa popular fuerte, en el sentido de que está vinculada a la celebración de un referéndum que las instituciones representativas no pueden evitar, pero que se limita a la reforma constitucional, sin que exista equivalente a nivel legislativo. Este es un instrumento poderoso, como vamos a ver, para que grupos minoritarios, no necesariamente vinculados a una determinada opción política representada en la Asamblea Federal, puedan incidir en el debate público.

Aunque la autoimagen constitucional de los suizos remite a una democracia tradicional, vinculada a la alte Schweizer Freiheit, que habría sido recuperada en el contexto de la actualización del marco político a través de la Constitución de 1848, lo cierto es que, en un primer momento, los elementos de democracia directa a nivel federal eran más bien escasos - otra cosa es lo que sucedía en algunos cantones, particularmente, en aquellos que funcionaban en régimen de Landsgemeinde- ${ }^{6}$. Sin embargo, es después de la primera Constitución federal que se produce la introducción significativa de instituciones de democracia directa a nivel cantonal, de modo que, en el momento de la primera revisión total de la Constitución (1872-1874), el conjunto de la confederación ya está madura para un avance significativo en este sentido ${ }^{7}$. Desde entonces, la democracia directa ha sido un elemento sustancial de la cultura política suiza, diferenciándola de la mayoría de los Estados de su entorno, donde más bien existe una

\footnotetext{
${ }^{5}$ Vid., por ejemplo, CROISAT, M., Le fédéralisme dans les démocraties contemporaines, Monchrestien, París, $1999^{3}$, p. 78.

${ }^{6}$ La Landsgemeinde es la asamblea del conjunto de los ciudadanos, de modo que el poder legislativo se ejerce directamente por el pueblo, aunque pueden existir elementos de democracia representativa (el Landsrat o el Grosser Rat) que, en cualquier caso, no ejercen el poder legislativo, sino la potestad reglamentaria. En estos momentos, funcionan aún en régimen de Landsgemeinde dos cantones: Glarus y Appenzell-Innerrhoden. Ello es posible debido a tratarse de cantones con una población más o menos reducida (unos 40.000 habitantes, en el caso del primero; y unos 15.000, en el caso del segundo). Sobre la Landsgemeinde, vid. mi trabajo "Las consultas populares en Suiza..." cit., pp. 142-143.

7 Vid. KÖLZ, A. "Geschichtliche Grundlagen”, Thürer, D., Aubert, J.-F., Müller, J. P. (eds.), Verfassungsrecht der Schweiz / Droit constitutionnel suisse, Schulthess, Zúrich, 2001, p. 121ss.
} 
desconfianza en relación con la participación directa del pueblo en las decisiones políticas $^{8}$.

Así, el referéndum legislativo facultativo se introdujo en 1874, siendo uno de los puntos clave del nuevo texto, en el marco de las concesiones que se hicieron a los sectores más democráticos después del fracaso del primer intento de revisión total de la Constitución de 1848, que el pueblo y los cantones rechazaron el 12 de mayo de 1872. La otra gran institución de democracia directa a nivel federal, la iniciativa popular de reforma de la Constitución, se introdujo un poco más tarde, en una votación que se llevó a cabo el 5 de julio de 1890. Es de esta institución de la que nos vamos a ocupar, en la medida en que la "Iniciativa para el paisaje" es justamente una manifestación de la iniciativa popular de reforma de la Constitución.

La iniciativa popular de reforma de la Constitución puede dirigirse hacia una reforma total de esta. En este caso, es necesario que el proceso sea iniciado por 100.000 ciudadanos con derecho a voto (art. 138.1 de la Constitución Federal, en adelante, CF). En este caso, se propone la reforma total de la Constitución, sin que se presente un nuevo texto en concreto que deba ser aprobado. Esta propuesta de revisión se somete a referéndum (art. 138.2 CF). Si recibe el apoyo del pueblo y los cantones — siempre es necesaria la doble mayoría para ganar un referéndum, de acuerdo con la estructura federal del Estado-, las dos cámaras de la Asamblea Federal se disuelven y los nuevos consejeros elegidos después de las elecciones correspondientes se encargan de impulsar la reforma constitucional (art. $193 \mathrm{CF}$ ).

\footnotetext{
8 La democracia directa ha suscitado considerables desconfianzas en una parte de la literatura iusconstitucionalista. Este ha sido particularmente el caso de Alemania, donde la experiencia de la República de Weimar no puede ser calificada de positiva en este sentido. Así, vid., por ejemplo, BÖCKENFÖRDE, E.-W., "Mittelbare/repräsentative Demokratie als eigentliche Form der Demokratie. Bemerkungen $\mathrm{zu}$ Begriff und Verwirklichungsproblemen der Demokratie als Staats- und Regierungsform", Staatsorganisation und Staatsfunktionen im Wandel. Festschrift für Kurt Eichenberger zum 60. Geburtstag, Helbing \& Lichtenhahn, Basilea-Frankfurt am Main, 1982, p. 306 ss. En relación con el caso de España, donde, claramente, la Constitución ha optado por conceder un margen ciertamente reducido a las instituciones de democracia directa, vid. RAMÍREZ, M., "El reforzamiento de la participación política", Revista de Derecho Político, núm. 36, 1992, pp. 27-45. De hecho, como ha puesto de manifiesto PÉREZ SOLA, N., "Algunas consideraciones en torno al derecho fundamental a la participación directa en los asuntos públicos", Revista de Derecho Político, núm. 41, 1996, p. 107, la Constitución española habría dado un trato devaluado a la participación directa, a pesar de su retórica democrática. El juicio sobre la democracia directa debe complementarse con un análisis crítico de la representación política en relación con el principio democrático. Para ello, vid. RUBIO LLORENTE, F., “Título III. Las Cortes Generales”, Alzaga Villamil, O. (dir.), Comentarios a la Constitución Española de 1978, Edersa, Madrid, 1998, p. 26 ss.
} 
Lo que nos ocupa, sin embargo, es una propuesta de reforma parcial de la Constitución. En ese caso, pueden instarla 100.000 ciudadanos, sea a través de una propuesta general o a través de un texto articulado. Ello determina el desarrollo del proceso posterior, que, en cualquier caso, finaliza con un referéndum. Si la iniciativa se presenta en forma de texto articulado, la Asamblea Federal puede formular una contrapropuesta y someterla a referéndum juntamente con el texto presentado por los ciudadanos (art. 139.5 CF). Cuando la Asamblea Federal formula una contrapropuesta, el sistema de voto se articula a través del doble sí, esto es, el elector se pronuncia sobre si está de acuerdo con la reforma constitucional y sobre cuál de las dos propuestas de reforma prefiere.

La jurisprudencia y la praxis de las autoridades federales han establecido una serie de condiciones para la validez de la iniciativa que, en algún caso, han sido introducidas en el texto constitucional. Son las siguientes: unidad de la forma (art. 139.3 CF), unidad de la materia (art. 139.3 CF), conformidad con las reglas imperativas del Derecho internacional (art. 139.3 CF) y, finalmente, ejecutabilidad ${ }^{9}$. Si cumple dichas condiciones, la iniciativa debe tramitarse y, finalmente, someterse - eventualmente, junto con una contrapuesta - a la decisión del pueblo. La "Iniciativa para el paisaje" es un caso de este tipo. Veámosla ahora con un cierto detenimiento

\section{LA "INICIATIVA PARA EL PAISAJE"}

\section{Origen y contenidos}

Ante la progresiva ampliación de la superficie construida en Suiza, los promotores de la "Iniciativa para el paisaje" opinan que se están produciendo impactos no deseables de consideración con repercusiones graves sobre el medio ambiente. De hecho, según datos oficiales hechos públicos por la Oficina Federal de Estadística, más de 100.000 nuevos edificios fueron construidos entre 2000 y 2005, de los que el 76\% correspondían a viviendas unifamiliares; la superficie de suelo industrial habría aumentado más del 24\% en los últimos veinticinco años (en el momento de la presentación de la iniciativa); mientras que la red de carreteras habría aumentado en 60.000 kilómetros en los últimos treinta y dos años. En definitiva, los promotores de la iniciativa constataron que la superficie construida había aumentado desde los años sesenta a un ritmo mucho más

\footnotetext{
${ }^{9}$ En relación con todo ello, vid. mi trabajo "Las consultas populares en Suiza...” cit., p. 130_ss.
} 
rápido que el crecimiento de la población, lo que daba lugar, según su opinión, a la necesidad de una intervención urgente de los poderes públicos, particularmente a nivel federal, que decidieron impulsar a través de una propuesta de reforma de la Constitución $^{10}$.

Esta situación, según el comité de la iniciativa, se podría calificar como un proceso de "urbanización galopante" que amenazaría la supervivencia de diferentes especies animales, destruiría la estructura del suelo, crearía nuevos riesgos para la ciudadanía y haría desaparecer espacios para el ocio. Asimismo, siempre según los promotores, la urbanización masiva y extensiva, sobre todo mediante viviendas unifamiliares, genera costes elevados en materia de servicios (agua, luz, etc.), disminuye la superficie cultivable y amenaza al turismo al degradar el entorno natural. Finalmente, el comité de la iniciativa consideró, asimismo, a la hora de hacer su propuesta, que la reserva de suelo urbanizable era suficiente como para cubrir las necesidades futuras, sin necesidad de ampliar la superficie hábil para construir durante un período prolongado de tiempo ${ }^{11}$. Por todo ello, presentaron el 10 de julio de 2007 su propuesta de reforma de la Constitución, en la que proponían lo siguiente:

- Modificación del primer párrafo del artículo 75 de la Constitución federal. El texto actual establece: "La Confederación determina los principios aplicables a la ordenación del territorio. Ello afecta a los cantones y sirve a una utilización juiciosa y mesurada del suelo y a una ocupación racional del territorio" ${ }^{\prime 2}$. Los promotores de la iniciativa, en cambio, defienden el texto siguiente: "La Confederación y los cantones velan por la utilización juiciosa y mesurada del suelo, por la ocupación racional del territorio, por la separación entre el territorio urbanizable y el no urbanizable, y por la protección de las tierras cultivables. Tomarán en consideración los imperativos de la ordenación del territorio en el cumplimiento de sus tareas"13.

\footnotetext{
${ }^{10}$ En relación con estos datos, vid. el mensaje del Consejo Federal en relación con la iniciativa (Message relatif à l'initiative populaire «De l'espace pour l'homme et la nature (initiative pour le paysage»), disponible en http://www.admin.ch/ch/f/ff/2010/945.pdf; recuperado el 8 de abril de 2011).

${ }^{11}$ Ibíd.

12 Texto a partir de la versión francesa oficial disponible en http:/www.admin.ch/ch/f/rs/101/a $75 . h t m l$ (recuperada el 8 de abril de 2011).

13 Texto a partir de la versión francesa de la iniciativa disponible en http://www.admin.ch/ch/f/pore/vi/vis356t.html (recuperada el 8 de abril de 2011).
} 
- Modificación del segundo párrafo del artículo 75 de la Constitución federal. En la actualidad, esta disposición determina: "La Confederación alienta y coordina los esfuerzos de los cantones y colabora con ellos"14. En la propuesta de modificación, en cambio, se dice: “La Confederación fijará los principios aplicables a la ordenación del territorio. Asimismo, aprobará las disposiciones dirigidas a desarrollar una urbanización de calidad en el interior de la trama construida y a restringir la construcción en el territorio no urbanizable. Además, alentará y coordinará la ordenación del territorio de los cantones"

- Abrogación del tercer párrafo del artículo 75 de la Constitución federal. Dado lo que se propone para el primer apartado del artículo 75, el actual párrafo tercero se considera ya innecesario ("En el cumplimiento de sus tareas, la Confederación y los cantones tomarán en consideración los imperativos de la ordenación del territorio") ${ }^{16}$.

- Nueva disposición transitoria en relación con el artículo 75. Lo más novedoso, sin embargo, es la propuesta de la introducción de una disposición transitoria para la aplicación del nuevo artículo 75, cuyo tenor literal es el siguiente: "La superficie total de las zonas hábiles para construir no podrá ser incrementada durante veinte años desde la aceptación el artículo 75. El Consejo Federal puede acordar derogaciones singulares para casos justificados" $" 17$.

En definitiva, la iniciativa persigue tres finalidades fundamentales, a saber: una mayor precisión constitucional de los límites para la política urbanística, una mayor incidencia de la Confederación en el desarrollo de dicha política y, finalmente, la fijación de una moratoria urbanística, que solo puede excepcionarse para supuestos justificados que corresponde apreciar, en todo caso, al Consejo Federal, esto es, el ejecutivo federal. Ello supondría una modificación considerable de la regulación urbanística en Suiza, y contribuiría a frenar el proceso de urbanización masiva que vive el país desde hace decenios.

\footnotetext{
14 Texto a partir de la versión francesa oficial disponible en http://www.admin.ch/ch/f/rs/101/a75.html (recuperada el 8 de abril de 2011).

15 Texto a partir de la versión francesa de la iniciativa disponible en http://www.admin.ch/ch/f/pore/vi/vis356t.html (recuperada el 8 de abril de 2011).

16 Texto a partir de la versión francesa oficial disponible en http://www.admin.ch/ch/f/rs/101/a $75 . h t m l$ (recuperada el 8 de abril de 2011).

17 Texto a partir de la versión francesa de la iniciativa disponible en http://www.admin.ch/ch/f/pore/vi/vis356t.html (recuperada el 8 de abril de 2011).
} 


\section{La contrapropuesta del Consejo Federal}

Dado que la propuesta de reforma de la Constitución se ha presentado en la forma de un texto articulado, de acuerdo con el artículo 139.4 CF, la Asamblea Federal puede formular una contrapropuesta, para ser sometida a la consideración del cuerpo electoral en el mismo referéndum que la iniciativa popular. Una vez constatado por la Cancillería Federal que la iniciativa cumplía los requisitos formales que impone la Constitución, el Consejo Federal presentó el 20 de enero de 2010 el correspondiente mensaje a la Asamblea Federal para que tramitara la iniciativa. En dicho mensaje, se proponía la adopción, por parte del Parlamento federal, de una contrapropuesta para ser sometida a la consideración del pueblo en el referéndum correspondiente.

La contrapuesta que el Consejo Federal presenta a la Asamblea Federal parte de la constatación del problema por parte del ejecutivo. Sin embargo, este considera que la reforma constitucional, y más en la forma que se propone, no constituye una solución adecuada. En este sentido, el Consejo Federal presenta una contrapropuesta indirecta a la Asamblea Federal, en la forma de una modificación sustancial de la actual Ley federal de Ordenación del Territorio.

Aparte de las consideraciones que el Consejo Federal hace en relación con la situación constatada por los promotores de la iniciativa, con cuyo análisis coincide esencialmente, y de las que realiza, asimismo, en relación con el reparto de competencias entre la Confederación y los cantones en esta materia, es interesante prestar atención a lo que opina en relación con la moratoria de veinte años, que constituye, sin duda, el núcleo central de la iniciativa. En este sentido, según el Consejo Federal, la medida castigaría a las comunas y los cantones que han hecho una utilización razonable del suelo, mientras que aquellos que han hecho una delimitación "demasiado generosa" del suelo urbanizable serían recompensados.

Por otro lado, una compensación supracantonal en relación con la superficie urbanizable a nivel federal no sería fácil, según el ejecutivo federal, ya que ello podría comportar un aumento de los precios del suelo y, en consecuencia, de la vivienda en aquellos lugares donde la superficie urbanizable fuera escasa, en la medida en que no existiría capacidad de reacción. Es cierto que la iniciativa atribuye al Consejo Federal la posibilidad de introducir excepciones a la moratoria, pero, según este, ello sería un mecanismo de 
reacción insuficiente, dado que no se prevé el procedimiento que debería seguirse en estos casos.

Por todo ello, se propone una modificación de la Ley de Ordenación del Territorio que, en opinión del Consejo Federal, respondería adecuadamente a la situación denunciada por la iniciativa. Dicha modificación, según el mismo ejecutivo federal, consistiría en “medidas rápidamente eficaces para limitar la extensión de la superficie urbanizable", la "promoción de un urbanismo de calidad en el interior de la trama construida" y un "dimensionamiento del suelo urbanizable en función de las necesidades"18.

\section{El debate actual y las consecuencias posibles del referéndum}

En el momento de escribir estas líneas y después de su tramitación en el Consejo de los Estados - la cámara de representación de los cantones en la Asamblea Federal-, donde se introdujeron modificaciones a la contrapropuesta indirecta del Consejo Federal en el sentido de una modificación parcial de la Ley federal de Ordenación del Territorio, se inició la tramitación en el Consejo Nacional, la cámara de representación popular. En la sesión celebrada el pasado 7 de diciembre, a propuesta del presidente se acordó la ampliación de un año para la tramitación de la iniciativa en dicha cámara, de modo que se fijó como nuevo plazo el 14 de febrero de $2012^{19}$.

El debate, pues, continúa abierto, concentrándose, como no podía ser de otro modo, en la parte más determinante de la propuesta, esto es, la moratoria urbanística. Deberá verse en los próximos meses cuál es la reacción del Consejo Nacional, aunque es previsible que, seguramente con alguna modificación, acabe aceptando presentar al cuerpo electoral una contrapuesta de acuerdo con el mensaje del Consejo Federal. En ese caso, el pueblo se encontraría ante la triple alternativa de rechazar ambas

\footnotetext{
${ }^{18}$ Para todo ello, vid. el ya citado mensaje del Consejo Federal en relación con la iniciativa. En concreto, sobre la reforma de la Ley de Ordenación del Territorio a través de una nueva Ley de Desarrollo Territorial, vid. el informe del Consejo Federal de 12 de diciembre de 2008 (disponible en: http://www.news-service.admin.ch/NSBSubscriber/message/attachments/18233.pdf, recuperado el 8 de abril de 2008). No es el objeto de este trabajo entrar en detalle en el análisis de dicho proyecto de ley, que, en cualquier caso, es cierto que propone una estrategia integral en la materia, mucho más compleja que la moratoria urbanística propuesta en la iniciativa popular, que, en cualquier caso, no se acepta.

19 Vid. Bulletin officiel - Les procès-verbaux du Conseil national et du Conseil des Etats (Conseil national - Session d'hiver 2010 - Sixième séance - 07.12.10-08h00) (http://www.parlament.ch/ab/frameset/f/n/4816/340909/f_n_4816_340909_340955.htm; recuperado el 8 de abril de 2011).
} 
propuestas, de aceptar la contrapropuesta de la Asamblea Federal (modificación de la Ley) o de aceptar la iniciativa popular (reforma de la Constitución).

Debe tenerse en cuenta que, en muchas ocasiones, las iniciativas populares de reforma de la Constitución son rechazadas por el pueblo, y, dado el texto de la que se presenta en este caso, es previsible que esto suceda de nuevo ${ }^{20}$. Sin embargo, debe notarse que, sea cual sea el resultado, la capacidad de impulsar la iniciativa ya ha generado un debate que, incluso en caso de rechazo, puede implicar la adopción de medidas significativas en la materia y, en todo caso, ha llevado a una toma de conciencia en relación con el problema. El caso de la propuesta de moratoria urbanística me sugiere algunas reflexiones sobre el principio de cooperación y el principio de precaución en materia urbanística que, según mi opinión, pueden ser de interés para el debate en España, insuficiente, en cualquier caso, dada la gravedad del problema.

\section{DE LO PARTICULAR A LO GENERAL. URBANISMO Y MEDIO} AMBIENTE

\section{La ordenación del territorio y el urbanismo como instrumentos para la gestión} del espacio

Entiendo que el medio ambiente, en cuanto bien jurídico, es el espacio físico global en el que se desarrolla la vida humana en cada momento histórico y que constituye la base para su propia pervivencia, siendo el resultado de la interacción histórica entre la naturaleza y la actividad humana que se proyecta sobre ella ${ }^{21}$. Por ello, creo que el Derecho urbanístico se presenta como un instrumento apropiado para la realización del mandato constitucional de protección contenido en el artículo 45 de la Constitución

Española (en adelante, CE), de modo que el bien jurídico del medio ambiente es tutelado, en parte, a través de la disciplina del uso del suelo, integrada también por las normas penales correspondientes en relación con las infracciones urbanísticas ${ }^{22}$.

${ }^{20}$ Desde 1893 se han sometido al pueblo y los cantones 173 iniciativas populares de reforma de la Constitución federal, de las que solo han sido aceptadas 17, lo que implica un porcentaje algo inferior al $10 \%$. Vid., en relación con esto, la estadística oficial disponible en: http://www.admin.ch/ch/f/pore/vi/vis_2_2_5_9.html, recuperada el 8 de abril de 2011.

${ }^{21}$ No puedo entrar en detalle en la defensa de esta concepción del medio ambiente. Lo he hecho, primero, en mi trabajo El concepte constitucional de medi ambient, Cambra de la Propietat Urbana de Reus, Reus, 2006, y, posteriormente, de manera más concisa ${ }_{2}$ en La cuestión ambiental y la transformación de lo público, Tirant lo Blanch, Valencia, 2011 [en prensa].

${ }^{22}$ La vinculación entre el Derecho urbanístico, la ordenación del territorio y la protección del medio ambiente es, de hecho, algo aceptado por buena parte de la doctrina. Así, por ejemplo, vid. BASSOLS COMA, M., "El medio ambiente y la ordenación del territorio", Documentación Administrativa, núm. 190, abril-junio 1981, pp. 407-439; del mismo autor, "Derecho urbanístico y medio ambiente urbano", Revista de Derecho Urbanístico, núm. 71, enero-febrero 1981, pp. 15-44; del mismo autor, "La planificación urbanística: su contribución a la protección del medio ambiente", Esteve Pardo, J. (coord.), Derecho del medio ambiente y administración local, Civitas, Madrid, 1996, pp. 397-425; FERNÁNDEZ, 
Ahora bien, en este espacio organizado a través del Derecho urbanístico y la ordenación del territorio, aparte de generar un medio ambiente adecuado para el desarrollo de la persona, hay que integrar la consideración de otros bienes jurídicos constitucionales, básicamente, el derecho a la vivienda (art. 47 CE) y el progreso social y económico (art. $40 \mathrm{CE}$ ), así como de los derechos constitucionales económicos, esto es, el derecho a la propiedad (art. 33.1 CE) y a la libertad de empresa (art. $38 \mathrm{CE}$ ). En este sentido, el diseño del espacio que deriva de la intervención urbanística se configura como una operación compleja que, en cualquier caso, debe cohonestar los distintos intereses en presencia con un resultado que se corresponda con un medio ambiente adecuado para las personas de hoy y las de mañana.

En definitiva, nos hallamos ante instrumentos normativos que se proyectan sobre el espacio para satisfacer un conjunto de necesidades sociales ${ }^{23}$. Esto tiene como resultado la particular complejidad de

las cuestiones relativas al urbanismo y la ordenación del territorio, donde bienes jurídicos e intereses protegidos muy diversos, pero, sobre todo, potencialmente en conflicto entre sí, confluyen en los procesos de toma de decisiones. En cualquier caso, es evidente que, ante esta confluencia de intereses, pueden

producirse desequilibrios no deseados cuando factores espurios presionan sobre el uso del suelo, postergando, explícita o implícitamente, algunos de los intereses en presencia, básicamente, en relación con lo que nos ocupa, la protección del medio ambiente y, en particular, del paisaje. La "Iniciativa sobre el paisaje" pone de manifiesto un caso particular de un desequilibrio de este tipo en que la presión sobre el territorio, con la connivencia de las autoridades, ha conducido a su progresiva degradación al servicio de intereses que se hallan más allá de los efectivamente protegidos por el Derecho.

\section{La vulnerabilidad del territorio y las necesidades sociales}

Habitualmente, a la hora de justificar la (sobre-)explotación del suelo, se acude a argumentos que tienen que ver con la necesidad de satisfacer el derecho a la vivienda reconocido en la Constitución, o con la necesidad de disponer de suelo para el desarrollo de determinadas actividades económicas que generan riqueza y, particularmente, puestos de trabajo. En la medida en que, desde un punto de vista constitucional, la promoción del progreso económico (y del pleno empleo) del artículo 40 CE y la satisfacción del derecho a la vivienda (artículo $47 \mathrm{CE}$ ) son bienes jurídicos análogos, voy a desarrollar la argumentación siguiente centrándome en el segundo de ellos. Mi objetivo aquí es mostrar cómo un objetivo constitucional legítimo que debe satisfacerse a través de la asignación de determinados usos al suelo puede contribuir a la

T. R., "Derecho, Medio Ambiente y Desarrollo", Revista Española de Derecho Administrativo, núm. 24, enero-marzo 1980, p. 11; LASAGABASTER HERRARTE I., GARCÍA URETA, A., "Intervención de los poderes públicos en materia ambiental: principios generales", Lasagabaster Herrarte, I., Derecho ambiental, IVAP/HAEE, Oñati, 2001, p. 55 ss.; MEZZETTI, L., "La costituzione dell'ambiente nel diritto pubblico comparato: modelli normativi, organizzazione amministrativa e situazioni giuridiche soggetive", Mezzetti, L. (ed.), I diritti della natura. Paradigmi di giuridificazione dell'ambiente nel diritto pubblico comparato, Cedam, Padua, 1997, p. 3; PAREJO ALFONSO, L., "Ordenación del territorio y medio ambiente", I Congreso Nacional de Derecho Ambiental. Ponencias, Sevilla, 1995, p. 116; RIVERO YSERN, E., "El ordenamiento jurídico nuclear y la ordenación y gestión del medio ambiente", Revista de Administración Pública, núm. 83, mayo-agosto 1977, pp. 59-97; VADRÍ I FORTUNY, M. T., "Planificación territorial, urbanística y ambiental. La planificación de residuos en Cataluña", Revista Vasca de Administración Pública / Herri-Arduralaritzazko Euskal Aldizkaria, núm. 48, mayo-agosto 1997, p. 343ss.

${ }^{23}$ En este sentido, por ejemplo, vid., TSCHANNEN, P., "Bau- und Nutzungsbeschränkungen aufgrund von umweltrechtlichen Vorschriften: Zusammenspiel von Umweltrecht und Raumplanung", Umweltrecht in der Praxis / Le Droit de l'environnement dans la pratique, 1998, p. 489. 
degradación del recurso utilizado, comprometiendo el disfrute de un medio ambiente adecuado por parte de los ciudadanos y la capacidad de las generaciones futuras de satisfacer sus necesidades legítimas.

Efectivamente, el Derecho urbanístico es un elemento clave para la generación de los recursos materiales que deben satisfacer el derecho a una vivienda digna, lo que se concreta en las decisiones particulares de planificación y calificación del suelo, que determinan, en última instancia, el parque de viviendas disponibles. La disponibilidad de viviendas destinadas a satisfacer el derecho constitucional del artículo 47 viene condicionada por dos factores, esencialmente, la existencia de viviendas suficientes y unas condiciones de acceso a estas que permitan su disfrute efectivo. En este sentido, es habitual poner el énfasis en la falta de viviendas suficientes para ampliar su número, lo que supone un uso mayor del espacio disponible y, con ello, un deterioro del medio ambiente.

Sin embargo, debe reconocerse que existe un número muy importante de viviendas desocupadas, de modo que las supuestas medidas encaminadas a una mayor extensión del suelo edificable responden, en realidad, a otros intereses, sea a una demanda de segunda residencia o plazas turísticas, que nada tiene que ver con el derecho a la vivienda, sea a pulsiones especulativas ${ }^{24}$. De hecho, la falta de disponibilidad de viviendas para satisfacer el derecho constitucional viene causada por la presión especulativa sobre el precio, que bloquea el acceso a la vivienda de sectores significativos de la población. Ello acaba repercutiendo en el precio final de la vivienda, lo que crea unas condiciones de acceso que, virtualmente, hacen ineficaz el derecho constitucional en muchos $\operatorname{casos}^{25}$. En este sentido, es obvio que una mayor urbanización no es la solución del problema, en la medida en que no estamos ante una escasez de viviendas, sino ante unas condiciones de distribución del parque existente que implican

\footnotetext{
${ }^{24}$ Según el Censo de Población y de Vivienda de 2001, en España había 3,1 millones de viviendas desocupadas, lo que suponía un $14,8 \%$ del total de las viviendas familiares, cuando el llamado "stock técnico en rotación" para permitir un funcionamiento apropiado del mercado inmobiliario no tendría que ser superior al 5\%, según explican VINUESA, J., DE LA RIVA, J. M., PALACIOS, A. J., en El fenómeno de las viviendas desocupadas, FUAM, Madrid, 2008 (http://www.uam.es/personal_pdi/filoyletras/juvian/documentos/DOC\%20Y\%20PUBLIC/2008\%20VIVI ENDA\%20DESOCUPADA.pdf), p. 8 (recuperado el 8 de abril de 2011).

${ }^{25}$ Vid. GARRIDO GUTIÉRREZ, P., "El derecho a la vivienda: ¿Un sueño irrealizable?”, García Herrera, M. A. (ed.), Constitución y democracia. 25 años de Constitución democrática en España (Actas del Congreso celebrado en Bilbao los días 19 a 21 de noviembre de 2003) (I), Servicio Editorial de la Universidad del País Vasco / Euskal Herriko Unibertsitateko Argitalpen Zerbitzua, Bilbao, 2005, p. 651.
} 
un precio de acceso muy elevado, lo que, por otro lado, impulsa las maniobras especulativas $^{26}$.

En definitiva, no parece que pueda ampararse en la satisfacción del derecho a la vivienda la intensa presión sobre el suelo, que, como en el caso de Suiza al que nos referíamos, está produciendo una degradación considerable del territorio, particularmente significativa y evidente en el caso de la costa mediterránea. En cuanto al desarrollo económico, debería verse si existe una auténtica necesidad de nuevo suelo industrial y no nos encontramos, como en el caso de la vivienda, con amplias bolsas de desocupación de la oferta existente. En relación con el turismo, en cualquier caso, debería conciliarse la oferta de plazas con un uso racional del suelo, de acuerdo con el artículo 45.2 CE. En cualquier caso, no parece que, efectivamente, necesidades objetivas y prioritarias expliquen la ocupación progresiva de territorio.

Más bien, deberían citarse factores como la financiación insatisfactoria de los ayuntamientos, las plusvalías fáciles que se generan en las maniobras especulativas, las disfunciones que la expectativa de beneficios rápidos y fáciles introduce en los controles públicos sobre el sector inmobiliario, así como la dependencia del sistema financiero de este ámbito de actividad ${ }^{27}$.

Así, los capitales se refugian en el sector inmobiliario, lo que incrementa la demanda y, en consecuencia, el precio del suelo, que repercute en la vivienda ${ }^{28}$. Ello estimula la inversión especulativa, de modo que la producción de plusvalías, provocada por la inyección de capital en el sector inmobiliario que impulsa la subida del precio de la vivienda, acaba haciendo que la oferta pierda su utilidad original, satisfacer la demanda de habitación, para devenir una inversión destinada a generar beneficio sin producir

\footnotetext{
${ }^{26}$ En este sentido, es evidente que, hasta la crisis de 2008, los precios de la vivienda crecieron de manera desproporcionada, lo que produjo un bloqueo significativo para la demanda existente, como pone de manifiesto, ciñéndose al caso de Cataluña, TRILLA BELLART, C., "La Ley del derecho a la vivienda: aspectos más destacados", Revista Catalana de Dret Públic, núm. 38, 2009, p. 2.

27 En este sentido, PISARELLO, G., "El derecho a la vivienda como derecho social: implicaciones constitucionales", Revista Catalana de Dret Públic, núm. 38, 2009, p. 9, enfatiza el uso sistemático que han hecho los ayuntamientos de la calificación como fuente de ingresos y los efectos que ello ha tenido en el sentido de estimular la especulación urbanística y, en última instancia, la corrupción. En este sentido, me remito a la comunicación presentada por el profesor Gonzalo Quintero en los I Encuentros junto al Mar ("Delitos urbanísticos y política criminal").

${ }^{28}$ Vid. TAMAMES, R., Diccionario de economía y finanzas, Alianza, Madrid, 1996, p. 263.
} 
valor añadido social real ${ }^{29}$. Con ello se genera una presión sobre el suelo que no responde a verdaderos intereses sociales amparados por el Derecho y, en última instancia, se crea un caldo de cultivo para la corrupción a nivel municipal, donde se concentran las competencias urbanísticas.

No debe perderse de vista, por otro lado, la dependencia de la economía española del sector de la construcción. Consiguientemente, no parece que existan estímulos a nivel supralocal para frenar la expansión urbanística, la correspondiente presión sobre el suelo, las maniobras especulativas y, en última instancia, la corrupción ${ }^{30}$. En cualquier caso, es evidente que este cúmulo de factores, lejos de impulsar la satisfacción de necesidades sociales constitucionalmente protegidas, favorece la degradación del territorio para la satisfacción de intereses especulativos estructurales. Ello demanda una respuesta amplia que genere un mayor control social sobre el uso del suelo, a través que la introducción de mecanismos de participación ciudadana en la política urbanística, como muestra el caso de la presión popular a través de la "Iniciativa para el paisaje", a la que me he referido en detalle en el apartado anterior.

\section{DESARROLLO SOSTENIBLE, PRINCIPIO DE PRECAUCIÓN Y PRINCIPIO DE COOPERACIÓN EN LA ORDENACIÓN DEL TERRITORIO: REFLEXIONES A PROPÓSITO DEL CASO SUIZO}

Queda claro, a mi juicio, que la presión sobre el suelo, que ha producido una degradación significativa del medio ambiente en una porción significativa del territorio español, no responde de manera clara y directa a la satisfacción de necesidades sociales como la generación de vivienda o de actividad económica y puestos de trabajo, fuera de lo que la propia construcción pueda hacer en este sentido, en el marco de un modelo económico que, por ese mismo motivo, es parasitario e insostenible. En este sentido, es obvio que se plantea la necesidad de limitar esa presión especulativa sobre el suelo en el

\footnotetext{
${ }^{29}$ Vid. CAPEL, H., Capitalismo y morfología urbana en España, Amelia Romero, Barcelona, 1983, p. 20 .

${ }^{30}$ El propio Tribunal Constitucional ha reconocido, incidentalmente, que el sector de la construcción se ha configurado como uno de los elementos clave en el modelo de desarrollo en España, con una gran capacidad de generación de empleo, lo que incide en las políticas que se diseñan para la gestión del suelo en nuestro país (vid. STC 152/1988, de 20 de julio de 1988, FJ 2. ${ }^{\circ}$ ).
} 
marco de un modelo global de desarrollo sostenible ${ }^{31}$. Dicho modelo, en particular, debería tener en cuenta la satisfacción de las necesidades sociales en relación con la vivienda, no perdiendo de vista la incidencia en las condiciones de acceso de factores que van más allá de la existencia física de viviendas — así, por ejemplo, una estructura del mercado claramente favorable a la especulación y, por lo tanto, al aumento desproporcionado del precio-.

En este contexto, sería de importancia particular, a la hora de revisar las reglas del juego vigentes en relación con el uso del suelo, la toma en consideración del principio de precaución como idea guía destinada a limitar el uso de un recurso natural extremadamente vulnerable como es el suelo, y a satisfacer verdaderas necesidades sociales, evitando actitudes parásitas basadas en análisis a corto plazo, que han sido y son las predominantes en la actualidad ${ }^{32}$. El principio de precaución debería regir la interpretación por parte de los tribunales de la legislación urbanística, de acuerdo con un marco constitucional que define al medio ambiente como bien jurídico, utilizando dicho marco en el control de las decisiones de la Administración ${ }^{33}$.

\footnotetext{
${ }^{31}$ La noción de desarrollo sostenible se formalizó a partir del informe titulado Nuestro futuro común, elaborado por la Comisión Mundial del Medio Ambiente y del Desarrollo, también conocido como Informe Brundtland, por el nombre de la presidenta de la citada comisión, la política noruega Gro Harlem Brundtland. En este texto se entiende por desarrollo sostenible aquel que satisface las necesidades del presente sin poner en peligro la capacidad de las generaciones futuras de satisfacer sus propias necesidades. Vid., en este sentido, COMISIÓN MUNDIAL DEL MEDIO AMBIENTE Y DEL DESARROLLO, Nuestro futuro común, Alianza Editorial, Madrid, 1988, p. 29. La idea de desarrollo sostenible ha sido utilizada por el Tribunal Constitucional en relación con el artículo $130 \mathrm{CE}$ (por ejemplo, en la STC 102/1995, de 26 de junio, FJ 4. ${ }^{\circ}$ ). Más allá, sobre esta idea, existe una bibliografía inmensa. A nivel orientativo, pueden citarse las siguientes referencias: ALDER, J., WILKINSON, D., Environmental Law \& Ethics, Macmillan, Londres, 1999, p. 127 ss.; y JOSITSCH, D., "Das Konzept der nachhaltigen Entwicklung (Sustainable Development) im Völkerrecht und seine innerstaatliche Umweltsetzung", Umweltrecht in der Praxis / Le Droit de l'environnement dans la pratique, 1997, p. 61 Ss.

${ }^{32}$ Sobre el principio de precaución, vid., entre otros, BENIDICKSON, J., Environmental Law, Irwin Law, Ottawa, 1997, p. 18 ss.; CALLIESS, C., Rechtstaat und Umweltstaat, Mohr Siebeck, Tubinga, 2001, p. 153 ss.; CECCHETTI, M., Principi costituzionali per la tutela dell'ambiente, Giuffrè, Milán, 2000, p. 169 ss.; ERBGUTH, W., Rechtssystematische Grundfragen des Umweltrechts, Duncker \& Humblot, Berlín, 1987, p. 92 ss.; KOECHLIN, D., Das Vorsorgeprinzip im Umweltschutzgesetz unter besonderer Berücksichtigung der Emissions- und Immissionsgrenzwerte, Helbing \& Lichtenhahn, Basilea-Frankfurt am Main, 1989, p. 10 ss.; ROMI, R., Droit et administration de l'environnement, Montchrestien, París, $2001^{4}$, p. 95 ss.; y SCHMIDT, R., Einführung in das Umweltrecht, Beck, Múnich, 1992³ , pp. 4-5.

${ }^{33}$ En cuanto al control de la actividad administrativa por parte de los tribunales ordinarios en relación con el respeto al derecho a un medio ambiente adecuado para el desarrollo de la persona, vid. mi trabajo $\mathrm{El}$ sistema constitucional de protecció del medi ambient, Institut d'Estudis Autonòmics, Barcelona, 2005, p. 104 ss. En este sentido, la posibilidad de instar el control de la constitucionalidad de la actividad administrativa se configuraría, a partir del derecho constitucional a un medio ambiente adecuado, como una funktionale Subjektivierung de la defensa del bien jurídico. En este sentido, vid. CALLIESS, Rechtstaat... cit., p. 485.
} 
Sin embargo, ello nos confrontaría con una posibilidad meramente reactiva en relación con el problema que nos ocupa. En relación con ello, creo que se tendrían que articular estrategias preventivas que deberían pasar por el establecimiento de mecanismos de participación ciudadana en el ámbito urbanístico, teniendo en cuenta la debilidad de los instrumentos de democracia directa en nuestro sistema. Efectivamente, el caso suizo muestra, a mi juicio, la virtualidad de los procesos democráticos a la hora de suscitar la atención de la opinión pública en relación con un determinado problema social. En este sentido, creo que valdría la pena reforzar los elementos de participación ciudadana en materia urbanística, porque ello contribuiría a la visibilidad de la toma de las decisiones y reforzaría el control social ${ }^{34}$. Dicha participación, en todo caso, debería abrirse a las organizaciones defensoras de intereses ambientales, en la medida en que los ciudadanos de un determinado municipio pueden, efectivamente, caer en la tentación desarrollista y convertirse en aliados de las maniobras especulativas sobre el territorio.

Sea como sea, ante la existencia de factores estructurales que favorecen la especulación urbanística y la presión sobre el suelo, el reforzamiento de los controles en la toma de decisiones es fundamental para responder a la situación. Ello implica, por supuesto, la aplicación efectiva del Derecho por parte de los tribunales ordinarios, maximizando las posibilidades que el marco constitucional les otorga en el control de la Administración. Más allá, es necesario reforzar los controles preventivos, que deben reposar en la participación ciudadana, ya que, en la situación actual, los incumplimientos en materia urbanística, por utilizar una expresión suave, son más bien la regla que la excepción, lo que obviamente impide trasladar a los tribunales toda la responsabilidad a la hora de reconducir la situación. En cualquier caso, el papel de los tribunales y de la opinión

\footnotetext{
${ }^{34}$ Particularmente, deberían optimizarse las posibilidades de participación que prevé el artículo 4, apartado e), de la Ley 8/2007, de 28 de mayo, del Suelo, en el sentido de que los ciudadanos puedan "[p]articipar efectivamente en los procedimientos de elaboración y aprobación de cualesquiera instrumentos de ordenación del territorio o de ordenación y ejecución urbanísticas y de su evaluación ambiental mediante la formulación de alegaciones, observaciones, propuestas, reclamaciones y quejas y a obtener de la Administración una respuesta motivada, conforme a la legislación reguladora del régimen jurídico de dicha Administración y del procedimiento de que se trate", en relación con el artículo 11 de la misma ley. En cualquier caso, debe subrayarse que la introducción de mecanismos de control social a través de la participación solo es funcional en la medida en que la Administración es transparente a la hora de informar a la ciudadanía de los procedimientos abiertos a su participación. En este sentido, vid., entre otros, ALONSO GARCÍA, E., "La participación de individuos en la toma de decisiones sobre el medio ambiente en España. Aspectos constitucionales", Revista Española de Derecho Administrativo, núm. 61, 1989, p. 49 ss.; CANOSA USERA, R., Constitución y medio ambiente, Dykinson, Madrid, 2000, p. 125; LOZANO CUTANDA, B., Derecho Ambiental Administrativo, Dykinson, Madrid, $2009^{10}$, p. 232 ss.; SÁNCHEZ MORÓN, M., "El derecho de acceso a la información en materia de medio ambiente", Revista de Administración Pública, núm. 137, 1995, p. 34.
} 
pública en el caso concreto debería desarrollarse en el marco de una revisión profunda del modelo económico que ha llevado a la situación de deterioro que vivimos. Aquí sí que, lamentablemente, no están a nuestra disposición los instrumentos de participación democrática que han llevado al debate sobre la moratoria urbanística en Suiza.

\section{BIBLIOGRAFÍA}

ALDER, J., WILKINSON, D., Environmental Law \& Ethics, Macmillan, Londres, 1999.

ALONSO GARCÍA, E., "La participación de individuos en la toma de decisiones sobre el medio ambiente en España. Aspectos constitucionales", Revista Española de Derecho Administrativo, núm. 61, 1989, pp. 49-65.

AUER, A., MAlinVERni, G., HOTTELIER, M., Droit constitutionnel suisse. 1. L'Etat, Staempfli, Berna, 2000.

BASSOLS COMA, M., "El medio ambiente y la ordenación del territorio", Documentación Administrativa, núm. 190, abril-junio 1981, pp. 407-439.

- "Derecho urbanístico y medio ambiente urbano", Revista de Derecho Urbanístico, núm. 71, enero-febrero 1981, pp. 15-44.

— "La planificación urbanística: su contribución a la protección del medio ambiente", Esteve Pardo, J. (coord.), Derecho del medio ambiente y administración local, Civitas, Madrid, 1996, pp. 397-425.

BENIDICKSON, J., Environmental Law, Irwin Law, Ottawa, 1997.

BÖCKENFÖRDE, E.-W., "Mittelbare/repräsentative Demokratie als eigentliche Form der Demokratie. Bemerkungen zu Begriff und Verwirklichungsproblemen der Demokratie als Staats- und Regierungsform”, Staatsorganisation und Staatsfunktionen im Wandel. Festschrift für Kurt Eichenberger zum 60. Geburtstag, Helbing \& Lichtenhahn, Basilea-Frankfurt am Main, 1982, pp. 301-328.

CALLIESS, C., Rechtstaat und Umweltstaat, Mohr Siebeck, Tubinga, 2001.

CANOSA USERA, R., Constitución y medio ambiente, Dykinson, Madrid, 2000.

CAPEL, H., Capitalismo y morfología urbana en España, Amelia Romero, Barcelona, 1983. 
CECCHETTI, M., Principi costituzionali per la tutela dell'ambiente, Giuffrè, Milán, 2000 .

COMISIÓN MUNDIAL DEL MEDIO AMBIENTE Y DEL DESARROLLO, Nuestro futuro común, Alianza Editorial, Madrid, 1988

CROISAT, M., Le fédéralisme dans les démocraties contemporaines, Monchrestien, París, $1999^{3}$.

ERBGUTH, W., Rechtssystematische Grundfragen des Umweltrechts, Duncker \& Humblot, Berlín, 1987.

FERNÁNDEZ, T. R., "Derecho, Medio Ambiente y Desarrollo", Revista Española de Derecho Administrativo, núm. 24, enero-marzo 1980, p. 5-16.

GARRIDO GUTIÉRREZ, P., "El derecho a la vivienda: ¿Un sueño irrealizable?”, García Herrera, M. A. (ed.), Constitución y democracia. 25 años de Constitución democrática en España (Actas del Congreso celebrado en Bilbao los días 19 a 21 de noviembre de 2003) (I), Servicio Editorial de la Universidad del País Vasco / Euskal Herriko Unibertsitateko Argitalpen Zerbitzua, Bilbao, 2005, p. 639-653.

JARIA I MANZANO, J., "El federalismo suizo. Una respuesta a una sociedad plural", Revista Vasca de Administración Pública / Herri-Arduralaritzako Euskal Aldizkaria, núm. 61 (I), septiembre-diciembre 2001, pp. 89-136.

- El sistema constitucional de protecció del medi ambient, Institut d'Estudis Autonòmics, Barcelona, 2005.

— "Las consultas populares en Suiza (Un estudio sobre la democracia directa)", Jus. Revista del Instituto de Investigaciones Jurídicas de la UJED, núm. 17, enero-junio 2009, pp. 127-144.

JOSITSCH, D., "Das Konzept der nachhaltigen Entwicklung (Sustainable Development) im Völkerrecht und seine innerstaatliche Umweltsetzung", Umweltrecht in der Praxis / Le Droit de l'environnement dans la pratique, 1997, pp. 93-121.

KOECHLIN, D., Das Vorsorgeprinzip im Umweltschutzgesetz unter besonderer Berücksichtigung der Emissions- und Immissionsgrenzwerte, Helbing \& Lichtenhahn, Basilea-Frankfurt am Main, 1989. 
KÖLZ, A., "Geschichtliche Grundlagen”, Thürer, D., Aubert, J.-F., Müller, J. P. (eds.), Verfassungsrecht der Schweiz / Droit constitutionnel suisse, Schulthess, Zúrich, 2001, pp. 111-127.

LASAGABASTER HERRARTE I., GARCÍA URETA, A., "Intervención de los poderes públicos en materia ambiental: principios generales”, Lasagabaster Herrarte, I., Derecho ambiental, IVAP/HAEE, Oñati, 2001, pp. 33-177.

LOZANO CUTANDA, B., Derecho Ambiental Administrativo, Dykinson, Madrid, $2009^{10}$.

MEZZETTI, L., “La costituzione dell'ambiente nel diritto pubblico comparato: modelli normativi, organizzazione amministrativa e situazioni giuridiche soggetive", Mezzetti, L. (ed.), I diritti della natura. Paradigmi di giuridificazione dell'ambiente nel diritto pubblico comparato, Cedam, Padua, 1997, pp. 3-22.

PAREJO ALFONSO, L., "Ordenación del territorio y medio ambiente", I Congreso Nacional de Derecho Ambiental. Ponencias, Sevilla, 1995, pp. 115-129.

PÉREZ SOLA, N., "Algunas consideraciones en torno al derecho fundamental a la participación directa en los asuntos públicos”, Revista de Derecho Político, núm. 41, 1996, pp. 97-118.

PISARELLO, G., "El derecho a la vivienda como derecho social: implicaciones constitucionales", Revista Catalana de Dret Públic, núm. 38, 2009, 1-13.

QUINTERO OLIVARES, G., "Delitos urbanísticos y política criminal”, ponencia no publicada, impartida en el marco de los I Encuentros junto al Mar. Acoso al Territorio, jornadas celebradas los días 13 y 14 de abril de 2011 en Santander y organizadas por la Facultad de Derecho de la Universidad de Cantabria.

RAMÍREZ, M., "El reforzamiento de la participación política", Revista de Derecho Político, núm. 36, 1992, pp. 27-45.

RHINOW, R., "Die Regierungsreform im Bund”, Zen-Ruffinen, P., Auer, A. (eds.), De la Constitution. Études en l'honneur de Jean-François Aubert, Helbing \& Lichtenhahn, Basilea-Frankfurt am Main, 1996, pp. 87-99.

RIVERO YSERN, E., "El ordenamiento jurídico nuclear y la ordenación y gestión del medio ambiente", Revista de Administración Pública, núm. 83, mayo-agosto 1977, pp. $59-97$. 
ROMI, R., Droit et administration de l'environnement, Montchrestien, París, $2001^{4}$.

RUBIO LLORENTE, F., “Título III. Las Cortes Generales”, Alzaga Villamil, O. (dir.), Comentarios a la Constitución Española de 1978, Edersa, Madrid, 1998, pp. 21-66.

SÁNCHEZ MORÓN, "El derecho de acceso a la información en materia de medio ambiente", Revista de Administración Pública, núm. 137, 1995, pp. 31-55.

SCHMIDT, R., Einführung in das Umweltrecht, Beck, Múnich, 1992³.

TAMAMES, R., Diccionario de economía y finanzas, Alianza, Madrid, 1996.

TRILLA BELLART, C., "La Ley del derecho a la vivienda: aspectos más destacados", Revista Catalana de Dret Públic, núm. 38, 2009, pp 1-12.

TSCHANNEN, P., "Bau- und Nutzungsbeschränkungen aufgrund von umweltrechtlichen Vorschriften: Zusammenspiel von Umweltrecht und Raumplanung”, Umweltrecht in der Praxis / Le Droit de l'environnement dans la pratique, 1998, pp. 486-513.

VADRÍ I FORTUNY, M. T., "Planificación territorial, urbanística y ambiental. La planificación de residuos en Cataluña", Revista Vasca de Administración Pública / Herri-Arduralaritzazko Euskal Aldizkaria, núm. 48, mayo-agosto 1997, p. 343-361.

VINUESA, J., DE LA RIVA, J. M., PALACIOS, A. J., en El fenómeno de las viviendas desocupadas, FUAM, Madrid, 2008 (http://www.uam.es/personal_pdi/filoyletras/juvian/documentos/DOC\%20Y\%20PUBLI C/2008\%20VIVIENDA\%20DESOCUPADA.pdf). 